International Journal of Molecular Sciences

ISSN 1422-0067

www.mdpi.com/journal/ijms

Correction

\title{
Correction: Vatani, A., et al. Prediction of Standard Enthalpy of Formation by a QSPR Model. Int. J. Mol. Sci. 2007, 8, 407-432.
}

\author{
Ali Vatani, Mehdi Mehrpooya * and Farhad Gharagheizi \\ Department of Chemical Engineering, Faculty of Engineering, University of Tehran, P.O.Box: 11365- \\ 4563, Tehran, Iran \\ * Author to whom correspondence should be addressed; E-mail: m.mehrpooya@gmail.com
}

Received: 23 February 2009 / Published: 24 February 2009

We found an error in our paper published in the Int. J. Mol. Sci. recently [1]: on page 409, the Equation (2) should be printed as:

$$
\Delta H_{f}{ }^{\circ}=50.1688-80.52012 n S K+53.64546 S C B O-169.21889 n O-174.75477 n F-266.57659 n H M
$$

We apologize for any inconvenience caused to the readers.

\section{References}

1. Vatani, A.; Mehrpooya, M.; Gharagheizi, F. Prediction of Standard Enthalpy of Formation by a QSPR Model. Int. J. Mol. Sci. 2007, 8, 407-432.

(C) 2009 by the authors; licensee Molecular Diversity Preservation International, Basel, Switzerland. This article is an open-access article distributed under the terms and conditions of the Creative Commons Attribution license (http://creativecommons.org/licenses/by/3.0/). 